\title{
Peer Learning as a Supplement to the Classroom Teaching- Using Peer Learning to Teach Interpreting
}

\author{
Yan Cao \\ Foreign Language School \\ East China University of Political Science and Law \\ Shanghai, China \\ Email: zoe_cao29@163.com
}

\begin{abstract}
Using peer learning as a supplement to the classroom teaching offers the opportunity to solve problems in traditional interpreting courses and enhance students' understanding and engagement in the interpreting practice. This study analyses the perceptions and attitudes of 35 students in an introductory course of interpreting taught at a Chinese university on the feedback given in peer review activities, based on their responses to the survey. Students worked in groups of three or four, where each member played different roles, such as the speaker, the interpreter or the reviewer. Results showed, among other aspects, that collaborative work and peer review among group members improved students' interpreting competence, and it also allowed the students to enhance interpersonal skills and critical thinking skill.
\end{abstract}

Keywords-peer learning; interpreting course; peer review; critical thinking; interpersonal skills

\section{INTRODUCTION}

Peer learning has been shown to be an effective mode of learning for all participants in different subjects. As an education practice originating from cognitive psychology that focuses on student interaction, the goal of peer learning is to impart the notion of self-learning [1] and to encourage critical thinking. According to Liu, Pysarchik, and Taylor [2], peer review is a type of peer learning practice, namely, a process of evaluating work performance and products by peers. Peer review enables students to gain greater levels of clarity, accuracy, and logical correctness when completing course exercises and assessments, as well as an exposure to the ideas of fellow students [3]. The opportunity to liaise with peers provides a unique platform for students to enhance their learning experience and associated assignment performance.

The opportunity for students to analyze the work of their peers, and to construct effective and concise feedback, can be seen as a form of collaborative learning associated with critical thinking, which may not only lead to the production of a higher-quality assignment and an improvement in assignment performance, but also contributes to the development of broader competencies needed in the interpreting profession.

While cooperative and interdependent learning techniques have been increasingly employed within the university environment, there is limited research examining peer learning, especially in relation to cooperative and systematic methods of feedback in an interpreting course.

The traditional method used to teach interpreting did not maximize student learning outcomes. The active learning strategy of peer review was used to enhance students' understanding and engagement in the interpreting practice. This active learning strategy involved small groups of students who worked together as a team to evaluate the interpreting performance of other team members. This article describes the development and incorporation of a peer review activity into an undergraduate interpreting course. The purpose of this study is to explore the effectiveness of peer learning as a supplement to the classroom teaching in the interpreting course.

Surveys are carried out with students after using peer learning for a semester. The results are presented and discussed, which lead to our conclusions. Results show that peer learning helps to improve interpreting competence, interpersonal skills and critical thinking skill among students. This study tries to use peer learning activities as a supplement to the traditional classroom teaching, and examines its effect through surveys.

\section{PREVIOUS RESEARCHES}

Peer learning is an education practice originating from cognitive psychology that focuses on student interaction with the goal of imparting the notion of self-learning [1] and the encouragement of critical thinking.

\section{Johnson and Johnson [4] emphasize that:}

“[...] there is no type of task on which cooperative efforts are less effective than are competitive or individualistic efforts, on most tasks [...] concept attainment, verbal problem-solving, categorization, spatial problem-solving, retention and memory, motor, guessing-judging-predicting, cooperative efforts are more effective in promoting achievement."

Scientific evidence indicates that effective peer interactions are characterized as stable, equitable, mutually engaging and reciprocal interactions. There is compelling evidence that assisted learning holds considerable potential to improve student performance [5], ensure outcome equity [6], enhance instructional efficacy and, most significantly, motivate students to learn and think together more deeply [7-9]. There is therefore a deepening consensus on the proposition that 
cooperative "interactive styles" [10] of classroom instruction are generally more effective than teacher-centered methods [11-12].

Student peer review, also referred to as peer editing, is a process in which students constructively evaluate the work of other students. At the college level, peer review can be used in many courses and disciplines, ranging from language courses to business courses to engineering courses [13-14]. Peer review allows and encourages students to take an active role in managing their own learning, as well as to strengthen students' CT skills [15].

Critical thinking definition changes with authors, and so various different definitions may be found. Still, all of them agree on the core competencies needed to become a critical thinker: the identification of the problem, the selection and analysis of relevant information, the recognition of inferences, the formulation of hypothesis, the drawing of conclusions and the establishment of judgment on the inferences [16]. Though educational policies keep stressing the importance of critical thinking skills for promotion of academic success and livelong learning, teaching and learning strategies emphasizing a more or less passive knowledge transfer is still common, especially in some language courses. Some teachers still focus on the student's ability to memorize bilingual expressions in translation and interpretation courses.

A number of studies covering fields ranging from second language learning to teacher training were found to be related to the purpose of the present research that explores participant perceptions of peer review. With regard to student reactions, Williams [17] weighed student preferences for different approaches to learning, and formulated categories to reflect their attitudes. The results indicated evidence in favor of self and peer evaluation as interesting activities. Moreover, it induced a positive perception in participants of their learning role. Brown and Dove [18] also explored how peer review affected students' attitudes. It was found that peer review led to greater involvement in learning, and brought about benefits such as increased motivation, better cooperation, and the sense of responsibility arising from increased learner autonomy.

\section{PEER REVIEW AS AN ACTIVE LEARNING STRATEGY IN AN INTERPRETING COURSE}

Peer learning is a helpful active pedagogy fostering the acquisition of knowledge and of personal and social skills resulting from the collaboration between the teacher and students, and among students in their working teams [19]. As important components of active learning and development of critical thinking skills process, peer review and feedback, allied to cooperative work, offer opportunities to foster critical thinking among students. Peer review on interpreting performance is a learning facilitator and promoter of communication and critical reasoning. In this study, students of an interpreting course were requested to work together to accomplish shared learning goals.

\section{A. Research Design}

This study involved 35 students of an introductory interpreting course at a Chinese university. The peer learning activity was developed to encourage students' autonomous learning after class. Students were meant to reinforce the interpreting skills learnt in class, interpersonal communication, collaborative work, and critical thinking.

All the students were organized in groups of three or four individuals. The teacher encouraged students to cooperate with those who were different in gender and interest, and change group members at regular intervals. In-class, instructions were given in order to familiarize students with the cooperative learning methodology, with the importance and the usefulness of peer review and critical thinking. Members in each group play the role of a speaker, an interpreter and a reviewer in turn. The peer learning activity was designed as follows:

1) 1st step - The speaker does brainstorming and writes an outline of a speech on a certain topic given by the teacher (the topic is related to in-class interpreting training). The speaker rehearses the speech with attention paid to public speaking skills.

2) 2nd step - The speaker gives the speech while the interpreter does consecutive interpretation for each segment of the speech.

3) 3rd step - The reviewer comments on the performance of the interpreter and the speaker and fills in a peer assessment form designed by the teacher, focusing on accuracy, fluency and articulacy.

4) 4th step - All group members have a discussion on the peer learning activity and collaboratively give their opinions and propose ways to avoid mistakes and errors in interpreting.

\section{B. Questionnaires}

Questionnaires were used to find students' attitude to peer learning and the effect peer learning has on student's interpreting and interpersonal skills. The satisfaction survey were divided in three parts, including closed and open-ended questions. The first part aimed to identify the basic information of students and the frequency of peer learning activities. The second part elicited students' opinion on the effectiveness of peer learning activities on the improvement of interpreting skills. Closed questions that identified particular skills demanded that students justify their choices in open questions, to minimize putative biases. The third part focused on the opinion of students about interpersonal skills and metacognitive skills they acquired through peer learning and peer review. To ensure that participant perceptions were objective, I put forward no opinions to the students and collected all data equally and impartially.

\section{Results}

A total of 35 copies of questionnaires were given to students of the experimental group. 32 valid questionnaires were recovered. The effective rate of recovery was $91.4 \%$. The survey tried to find the average frequencies of peer learning activities per week, the average length of each peer learning activity, the location of peer learning activities, the challenges and rewards of playing different roles in peer learning activities, the effect of peer learning activities on improving interpreting skills, etc. 
Generally speaking, the students' perceptions of the use of peer review in the interpreting course were favorable. They considered it to be an effective activity. They commented that its use had provided them an efficient learning tool and had enhanced their interpreting skills and critical thinking skill. Some students also mentioned that it had created a more positive learning environment and created a sense of group cohesion.

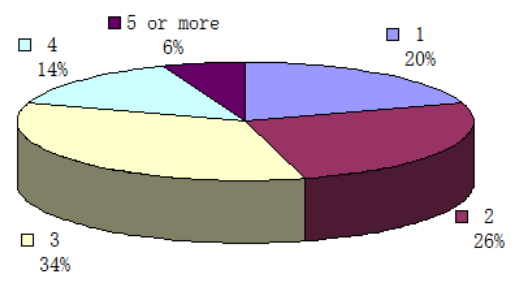

Fig. 1 The Frequency of Peer Learning Activities Each Week

Figure 1 showed how often students had peer learning activity each week. Most students had two to three peer learning activities each week. The teacher did not supervise after class autonomous learning all the time. Since the experimental group worked in groups, group members worked interdependently, and pushed each other to spend more time practicing interpreting and work harder. Interdependent learning was proved to be more effective and efficient than independent learning.

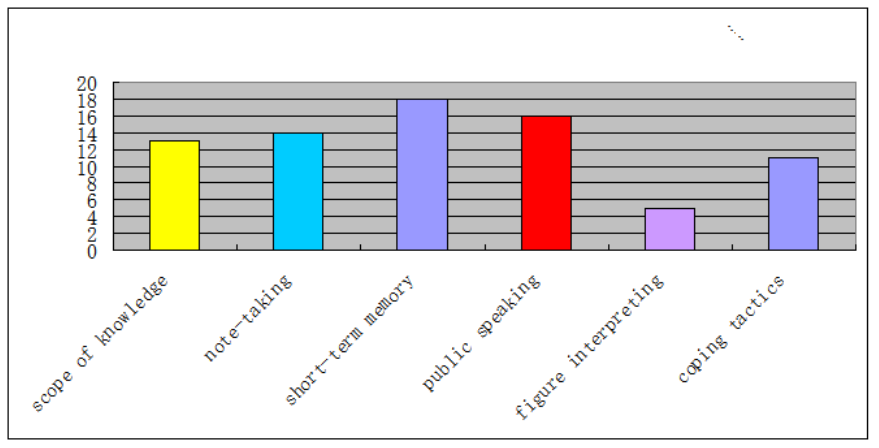

Fig. 2 Improvement of Interpreting Skills in Peer Learning

From Figure 2, we can see, among the 35 students in the experimental group, 18 students find peer learning activities help them improve short-term memory; 16 students believe they have made progress in public speaking skill; 14 students find their note-taking skill has been improved. A considerable number of students agree peer learning activities are helpful in enhancing their interpreting skills like scope of knowledge, coping tactics and figure interpreting.

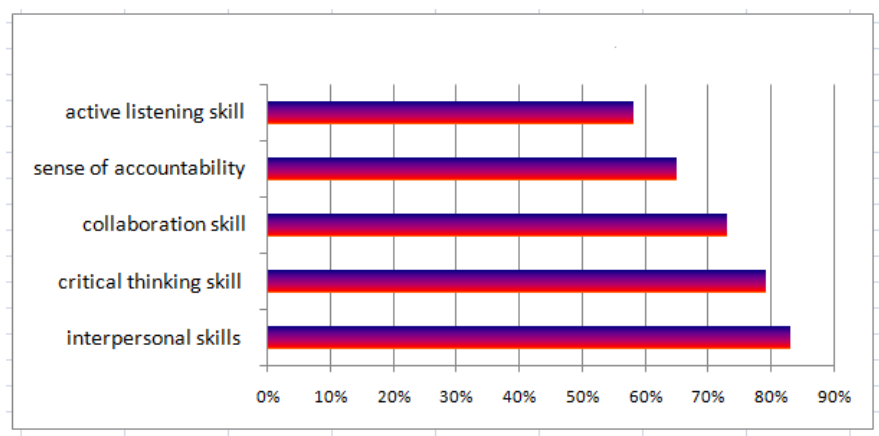

Fig. 3 Improvement of Interpersonal and Other Skills

Figure 3 showed, globally, $83 \%$ of the students considered the peer learning activity increased their interpersonal skills. $79 \%$ agreed/strongly agreed that the peer review activity was effective in improving critical thinking skills. About $73 \%$ of them agreed/strongly agreed that the peer review activity was important for their training, and also considered that it allowed them to improve their collaboration skills and become better team players. Moreover, $65 \%$ thought that the activity improved their sense of accountability. 58\% of them felt they improved their active listening skills and their respect for others' opinions. In answering open-ended questions in the survey, students reported that they learnt to cope with pressure and accept constructive feedback and they found they became more flexible through working with other team members and commenting on each others' performance.

\section{DISCUSSION AND CONCLUSION}

Development of critical thinking remains underestimated in the teaching of interpretation, despite being contemplated within the educational policies. This study examines the impact of peer learning as a supplement to the traditional classroom teaching in an introductory course of interpreting taught at a Chinese university. Students were asked to participate in peer learning activities designed for the interpreting course. Each student completed a survey after taking part in the peer learning activities for one semester. The active learning strategy of peer review was used to encourage students' autonomous learning and engagement in interpreting practice. This active learning strategy involved small groups of students who worked together as a team to evaluate the performance of each other using a peer evaluation form.

Previous research suggests that peer learning is far more effective than traditional classroom lectures. Results from this study support this theory in that the peer students found their interpreting competence and interpersonal skill were enhanced through peer review. Consistent with the literature, students encourage and support each other, assume responsibility for their own and each other's learning, employ group related interpersonal skills, and evaluate each others' progress. Working together also promotes the students' skills for their learning autonomy.

Our survey proved peer review was an effective activity for supporting critical thinking and reflective practice. As a cooperative tool, it promoted skills related to critical thinking, active listening and communication. When performing peer 
review, students actively participated in the overall learning process. They had the opportunity to interact with different perspectives and opinions, analyze critically the ideas, comment, compare the work, give and receive feedback that can be used to enhance their own work. These skills have the potential to enable students to become lifelong reflective learners, which is an essential quality of excellent interpreters. Apart from its efficacy as a strategy of active learning, it may also have the potential to provide the teacher with a means to monitor the quality of students' interpreting practice out of class. Peer review should be considered an important component to interpreter training and included as an effective teaching tool for interpreting courses in the future.

However, there is no denying that students' peer review may be influenced by certain subjective factors. It is worth noting that we examine student peer review, with an emphasis on collaborative learning and critical thinking, rather than peer grading. The teacher, whose role is a facilitator, always guides on the side to make sure students understand the only way to complete the project successfully is for each member to contribute part of the tower they are building. The teacher is there to intervene if there are problems or questions concerning peer review. The teacher helps students reflect on how well they work as a group and what they can do to help their group be successful.

\section{REFERENCES}

[1] Oldfield, Keith A.; Macalpine, J. Mark K. (1995).Assessment \& Evaluation in Higher Education, 20(1) : 125-32.

[2] Liu, Jianguo; Pysarchik, Dawn Thorndike; Taylor, William W.(2002).Peer Review in the Classroom. Bioscience, 52(9): 824-29.

[3] Bassham, G.; Irwin, W.; Nardone, H.; \& Wallace, J. (2011). Critical thinking: A student's introduction. 4th Ed. New York, NY: The McGraw Hill Companies.

[4] Johnson D. W., Johnson R. T. (1983). "The socialization and achievement crises: are cooperative learning experiences the solution?" in Applied Social Psychology Annual 4, ed. Bickman L., editor. New York: Sage Publications, 119-164.

[5] Kayi-Aydar H. (2013). Scaffolding language learning in an academic ESL classroom. ELT J. 67, 324-335.

[6] Hedin D. (1987). Students as teachers: a tool for improving school climate and productivity. Soc. Policy 17, 42-47.

[7] Sivan E. (1986). Motivation in social constructivist theory. Educ. Psychol. 21, 209-233.

[8] Hickey D. (1997). Motivation and contemporary socio-constructivist instructional perspectives. Educ. Psychol. 32, 175-193.

[9] Mercer N. (2000). Words and Minds: How We Use Language to Think Together. London: Routledge.

[10] Black P., Wiliam D. (2006). "Assessment for learning in the classroom," in Assessment and Learning, ed. Gardner J., editor. London: Sage, 9-25.

[11] Cauley M. C., McMillan J. H. (2010). FA techniques to support student motivation and achievement. Clear. House 83, 1-6.

[12] Clark I. (2014). Equitable learning outcomes: supporting economically and culturally disadvantaged students in 'Formative Learning Environments'. Improv. Sch. 17, 1-27.

[13] Topping, Keith. (2003). "Self and Peer Assessment in School and University: Reliability, Validity and Utility.” Pp. 55-87 in Optimizing New Modes of Assessment: In Search of Qualities and Standards, edited by M. Segers, F. Dochy, and E. Cascallar. Dordrecht, Netherlands: Kluwer.

[14] Rieber, Lloyd. (2006). "Using Peer Review to Improve Student Writing in Business Courses." Journal of Education for Business 81(6): 322-25.

[15] Pearce, J., Mulder, R., \& Baik, C. (2009). Involving students in peerreview: case studies and practical trategies for university teaching. Melbourne: Centre for the Study of Higher Education, University of Melbourne.

[16] Ennis, R. (2011) The Nature of Critical Thinking: An Outline of Critical Thinking Dispositions and Abilities. Retrieved from [http://faculty.education.illinois.edu/rhennis/documents/TheNatureofCrit icalThinking_51711_000.pdf]

[17] Williams, E. (2002). Student attitudes towards approaches to learning and assessment. Assessment and Evaluation in Higher Education. 17(1): $45-48$.

[18] Brown, S. \& Dove, P. (2001). Self and Peer Assessment. Birmingham, England, SCED Publications.

[19] Tsay, M., \& Brady, M, (2010). A case study of cooperative learning and communication pedagogy: Does working in teams make a difference? Journal of the Scholarship of Teaching and Learning, 10(2), 78-89. 